\title{
Oral Ethanol Self-Administration in Rhesus Monkeys: Behavioral and Neurochemical Correlates
}

\author{
J. A. Vivian, J. D. Higley, M. Linnoila, ${ }^{\dagger}$ and J. H. Woods
}

\begin{abstract}
Background: Previous research has revealed that orally administered ethanol serves as a reinforcer in nonhuman primates. The purposes of the present study were to examine the relationship between ethanol preferences and intakes in two distinct self-administration contexts and to reveal some of the behavioral and neurochemical correlates of oral ethanol self-administration in monkeys.

Methods: Three cohorts of 13 to 29 rhesus monkeys (Macaca mulatta) were socially housed and given daily, 1-hr, one-spout access to an ethanol solution $(8.4 \%, \mathrm{w} / \mathrm{v})$ sweetened with aspartame. Twelve of these monkeys were subsequently selected, individually housed, and given daily, 2 -hr, two-spout access to a range of ethanol concentrations $(0.25-16 \%, w / v)$ concurrently with water.

Results: These monkeys (National Institute on Alcohol Abuse and Alcoholism group) showed a marked preference for ethanol $(0.5-4 \%, \mathrm{w} / \mathrm{v})$ over water, and ethanol preferences were 3 -fold greater than those of a second group of 12 monkeys (University of Michigan group) purchased from a commercial vendor. Ethanol consumption was consistent across the self-administration paradigms. Monkeys that consumed large quantities of ethanol under the one-spout, social-housing conditions continued to drink large quantities of ethanol under the two-spout, individual-housing conditions $(r=0.86)$. An association between ethanol preferences and intakes was also demonstrated. Monkeys with the greatest preferences for ethanol over water under the two-spout choice conditions consumed the largest quantities of ethanol $(r=0.82)$. Finally, cerebrospinal fluid 5-hydroxyindoleacetic acid concentrations were inversely related to ethanol preference but not to ethanol intake.

Conclusions: These results indicate that ethanol consumption is stable across contexts and is positively corrclated with the preference for ethanol over water.
\end{abstract}

Key Words: Ethanol, Preferences, Self-Administration, Serotonin.

$\mathbf{P}$ RECLINICAL STUDIES using intravenous selfadministration techniques with monkeys have provided a wealth of information regarding drugs likely to serve as reinforcers in human subjects; with few exceptions, the abuse liability of the tested compounds and the receptor system underlying the behavioral effects could be determined (Deneau et al., 1969; Zernig et al., 1997). However, the intravenous method may not be an appropriate model for human drug abuse in other ways. For example, the enormously different individual patterns of human ethanol consumption, with a small proportion of the population consuming disproportionately large quantities of alcohol (O'Brien, 1996), is not modeled well by the intravenous model of ethanol abuse, in which virtually all monkeys show

From the Department of Pharmacology (J.A.V., J.H.W.), University of Michigan Medical School, Ann Arbor, Michigan, and the Laboratory of Clinical Studies (J.D.H., M.L.), National Institute on Alcohol Abuse and Alcoholism, Bethesda, Maryland.

Received for publication February 4, 1999; accepted June 9, 1999.

† Deceased.

This work was supported by United States Public Health Service Grants AA11424, DA00254, and DA05773.

Reprint requests: Jeffrey A. Vivian, Ph.D., Department of Pharmacology, University of Michigan Medical School, 1301 MSRB III, Ann Arbor, MI 48109-0632; Fax: 734-764-7118; E-mail: jvivian@umich.edu

Copyright $(1999$ by the Research Society on Alcoholism. consistently high ethanol intakes (Karoly et al., 1978; Williams et al., 1998; Winger, 1988; Winger and Woods, 1973).

The reinforcing effects of a number of orally available drugs have been demonstrated in monkeys (Carroll and Stotz, 1983; Henningfield and Meisch, 1979). Although subjects typically demonstrate reinforcing effects of the drugs tested, there has been little or no emphasis placed on individual differences among subjects in their proclivities to exhibit reinforcing effects (Higley et al., 1996; Juarez et al., 1993; Kraemer and McKinney, 1985). We are intrigued by individual differences among subjects because they may indicate that the oral route of administration dampens the reinforcing effects of the drugs in such a way as to make their acceptability more like that demonstrated in human subjects. In other words, it may be possible to use individual differences in the reinforcing effects of orally administered drug solutions among animals to model individual differences in drug and alcohol abuse in the human population.

In contrast to primates, individual and strain differences in oral ethanol self-administration have been well documented in rodents. Researchers have selectively bred rodents for divergent ethanol consumption. This selective breeding resulted in the establishment of preferring $(\mathrm{P})$ and nonpreferring (NP) (Li et al., 1994), high and low alcohol consumer (Mardones and Segovia-Riquelme, 1983), alco- 
hol and nonalcohol (Erikkson, 1972), and high- and lowalcohol-drinking ( $\mathrm{Li}$ et al., 1994) rats, which demonstrate nonoverlapping high and low intakes of ethanol, respectively. Results from studies using these rats suggest a genetic component of ethanol consumption that is in accordance with that of human subjects (Cloninger, 1987; Prescott and Kendler, 1999).

Compromised serotonin [5-hydroxytryptamine (5-HT)] function has been implicated in alcoholism and nonhuman ethanol self-administration. Low concentrations of the cerebrospinal fluid (CSF) 5-HT metabolite 5-hydroxyindoleacetic acid (5-HIAA) and reduced levels of 5-HT transporters have been demonstrated in individuals at risk for alcoholism and impulse control problems, such as aggression, arson, and suicide (Ballenger et al., 1979; Borg et al., 1985; Heinz et al., 1998; Virkkunen et al., 1994). Rhesus monkeys with low CSF 5-HIAA concentrations consumed large quantities of a sweetened ethanol solution, even when the sweetened vehicle was concurrently available (Higley et al., 1996). Moreover, the 5-HT 1 A partial agonist buspirone decreased ethanol, but not water, intake in macaques (Collins and Myers, 1987). Low 5-HT and 5-HIAA concentrations were consistently observed in P and high-alcohol-drinking rats (Gongwer et al., 1989; Murphy et al., 1987), as well as in some other rodent species with ethanol preferences (Fawn-Hooded and Sardinian alcohol-preferring rats and C57BL mice) (Devoto et al., 1998; Rezvani et al., 1990; Yoshimoto and Komura, 1989). Although acute administration of 5-HT agonists, reuptake blockers, and releasing agents decreased ethanol intake in rats, the selectivity of these 5-HT manipulations for ethanol self-administration is questionable (for review, see LeMarquand et al., 1994). Nevertheless, these experiments provide an attractive impetus for further investigations of the relationship between central 5-HT function and ethanol selfadministration.

Until recently, primate research has contributed surprisingly little of importance to our understanding of individual differences in oral ethanol self-administration. Therefore, the objectives of the present study were (1) to determine the preferences for and consumption of unsweetened ethanol solutions, over a range of ethanol concentrations, in a large group $(n=24)$ of rhesus monkeys; (2) to determine whether ethanol intake in one environment predicts subsequent ethanol intake in a different environment; and (3) to evaluate some of the behavioral and neurochemical correlates of oral ethanol self-administration.

\section{METHODS}

\section{Subjects}

Two groups of rhesus monkeys (Macaca mulatta) were used in these studies. The first group included threc cohorts of 13 to 29 monkeys that were established at the National Institute on Alcohol Abuse and Alcoholism (NIAAA) primate facility in Poolesville, Maryland. These monkeys $(n=61)$ were group-housed in large indoor/outdoor pens and were allowed to interact freely and establish social hierarchies, with free access to food and water. At approximately 48 months of age, each monkey was given a single administration of ethanol ( $2 \mathrm{~g} / \mathrm{kg}$, intravenously); at approximately 50 to 51 months of age, one-spout oral self-administration experiments were performed as described below. At approximately 57 months of age, 12 monkeys ( 7 males and 5 females, $4.2-9.5 \mathrm{~kg}$ ) were transferred to the facilities at the University of Michigan and housed as described below. The second group included 12 age-matched monkeys ( 6 males and 6 females, $4.9-7 \mathrm{~kg}$ ) that were purchased from a commercial vendor and housed as described below [University of Michigan group (MICH)]. Before transfer to the University of Michigan (at 36 months of age), these monkcys were group-housed in large indoor/outdoor pens at Yerkes Regional Primate Center and were allowed to interact freely and establish social hicrarchies, with free access to food and water.

After transfer to the University of Michigan, the 13 male and 11 female young adult rhesus monkeys were individually housed, with free access to water, in a vivarium maintained at $21 \pm 11^{\circ} \mathrm{C}$ and 30 to $50 \%$ humidity, with a 12:12-hr light/dark cycle. Monkeys were fed approximately 25 biscuits (Purina Monkey Chow) each day and fresh fruit twice each week.

NIAAA and MICH monkeys were exposed to one-spout panel training sessions (see below) at approximately 60 and 38 months of age, respectively. MICH monkeys were also exposed to unsweetened methadone, using a one-spout oral self-administration procedure, at 39 to 42 months of age. Two-spout, oral, ethanol self-administration testing sessions (described below) were performed when NIAAA monkeys were approximately 60 to 64 months of age and when MICH monkeys were approximately 48 to 52 months of age. Experimental sessions were conducted in the homecage.

Finally, both groups of monkeys were born and raised in breeding colonies; no subject selection criteria were used (i.e., the NIAAA monkeys were not chosen because of excessive ethanol consumption, excessive "impulsiveness" or aggression, or compromised CSF 5-HIAA concentrations; $\mathrm{MICH}$ monkeys were unexceptional in their procurement and were relatively undisturbed until transport from the primate center). The approximate behavioral histories of the monkeys are presented in Fig. 1 (for additional details on the NIAAA monkeys, see Higley et al., 1991). Animals used in these studies were maintained in accordance with the University of Michigan Committee on Animal Care standards and the Guidelines of the Committee on the Care and Use of Laboratory Animal Resources, National Health Council (Department of Health, Education, and Welfare, ISBN 0-309-05377-3, revised 1996).

\section{Apparatus}

One-Spout Oral Self-Administration. In Poolesville, six polycarbonate drinking chambers $(46 \times 22 \times 28 \mathrm{~cm})$ with one stainless steel drinking spout and a perch were placed in the outdoor portion of the homecage. Each chamber housed one monkey at a time and allowed drinking without disturbance from other colony members (for details, see Higley et al., 1996). Monkeys could see each other while in the drinking chambers.

Two-Spout Oral Self-Administration. In Michigan, an operant panel for fluid delivery and response measurement was attached to one wall of the homecage $(61 \times 69 \times 76 \mathrm{~cm})($ Henningfield and Meisch, 1976). This panel contained two drinking spouts (diameter, $1.2 \mathrm{~cm}$; length, $2.7 \mathrm{~cm}$ ) that protruded into the cage and were positioned $30 \mathrm{~cm}$ from each other and below two light-emitting diodes. Lip contact with the drinking spouts defined a response and completed a drinkometer circuit, which opened a solenoid for fluid delivery $(0.5 \mathrm{ml})$. During the sessions, the light-emitting diodes were illuminated green to signal fluid availability and red to signal spout contact. Additional discriminative stimuli associated with spout contact were provided by an audible click when the solenoids were operated. Experimental sessions were controlled and data were collected with IBM-compatible computers in an adjacent room.

\section{Procedures}

One-Spout Oral Self-Administration. In Poolesville, NIAAA monkeys were trained to enter the polycarbonate drinking chambers to obtain fruit; these daily 1-hr sessions also provided access to an aspartame-sweetened vehicle through the drinking spout. Monkeys were then exposed to daily 


\section{Behavioral history}

NIAAA monkeys

Neonatal testing: temperament, CNS integrity (1 wk) CSF: 5-HIAA, MHPG, HVA

Blood: ACTH, cortisol, prolactin

Behavior: anxiety, withdrawal, activity $(1-6 \mathrm{mo})$

Separation: $4 \times 4$ d $(6 \mathrm{mo})$

CSF / Blood / Behavior (6-8 mo)
CSF / Blood / Behavior IV ethanol $(2 \mathrm{~g} / \mathrm{kg})$ : intox. and agg. rating ( $48 \mathrm{mo})$

Oral self-administration (50-51 mo)

- Ethanol $(8.4 \%$ w/v $)$

- aspartame sweetened

- single-spout access

CSF / Blood / Behavior

transport to Michigan (57 mo)

CSF
Oral ethanol self-administration (60-64 mo) - Ethanol $(0.25-16 \% \mathrm{w} / \mathrm{v})$

- unsweetened

- two-spout access

\section{MlCH monkeys}

Fig. 1. Approximate behavioral histories of NIAAA and MICH monkeys serving as subjects for the current experiments. CNS, central nervous system; 5H1AAA, 5-hydroxyindole acetic acid; MHPG, methoxyhydroxyphenylglycol; HVA, homovanillic acid; ACTH, adrenocorticotropic hormone; IV, intravenous; intox., intoxication; agg., aggression; PET, positron emission tomography. 1-hr sessions of aspartame-sweetened ethanol $(8.4 \%, \mathrm{w} / \mathrm{v})$ access, through one spout, for 5 consecutive days in 4 consecutive weeks. Water was not available in the $1 \mathrm{hr}$ immediately before the test sessions, and the daily food ration was not altered.

Two-Spout Oral Self-Administration

Panel Training. In Michigan, NIAAA and MICH monkeys were initially exposed to 2-hr sessions of water access through one of the two spouts. Delivery of the fluid $(0.5 \mathrm{ml})$ was contingent on one-spout contact (fixed ratio of 1). The spout that delivered water was determined randomly in blocks of six sessions, and the daily food ration was delivered immediately before the session to promote drinking behavior (prandial drinking). NIAAA and MICH monkeys were exposed to these training conditions for
11 and 30 sessions, respectively. Ethanol was not available during this portion of the study.

Testing. Monkeys were then exposed to 2-hr sessions with concurrent access to water and ethanol through both spouts. Fluid delivery $(0.5 \mathrm{ml})$ was contingent on one-spout contact (fixed ratio of 1). The spouts that delivered ethanol and water were determined randomly in blocks of six sessions, and the daily food ration was delivered after the experimental session (i.e., there were no induction procedures). Ascending concentrations of unsweetened ethanol $(0,0.25,0.5,1,2,4,8$, and $16 \%$, w/v) were available in blocks of six sessions [the duration of ethanol exposure (6-30-day determinations with a single concentration) did not influence the preference for or consumption of ethanol for these monkeys], and 
replications of selected concentrations spanning the concentration-effect curve were performed in the following order for all monkeys: $0,2,0.25,8$, and $1 \%(\mathrm{w} / \mathrm{v})$.

Blood Sampling and Blood Ethanol Concentrations (BECs). Immediately after selected two-spout self-administration sessions, monkeys were anesthetized with ketamine hydrochloride $(10 \mathrm{mg} / \mathrm{kg}$, intramuscularly), and the calf of one leg was shaved and cleaned with ethanol and betadyne. Blood samples of approximately $1 \mathrm{ml}$ were collected, through a 22-gauge $(3.8-\mathrm{cm})$ needle, from the saphenous vein and placed in test tubes containing ethylenediaminetetraacetate $(7.5 \%)$. BECs were determined with a commercially available nicotinamide adenine dinucleotide-alcohol dehydrogenase spectrophotometric assay (catalog number 332-C; Sigma Chemical Co., St. Louis, MO), with inter- and intra-assay variabilities of less than $1 \%$.

CSF Sampling and 5-HIAA Concentrations. Before the two-spout selfadministration experiments, monkeys were anesthetized with ketamine hydrochloride $\left(10 \mathrm{mg} / \mathrm{kg}\right.$, intramuscularly), and a $10-\mathrm{cm}^{2}$ area at the base of the skull was shaved and cleaned with ethanol and betadyne. Approximately $2 \mathrm{ml}$ of CSF was collected from the cisterna magna using a 22-gauge $(3.8-\mathrm{cm})$ needle. This was accomplished by inserting the needle through the skin at the midline, approximately $2 \mathrm{~cm}$ below the external occipital protuberance, and determining the position of the skull. The skull was gently probed with the needle, following the occipital bone (advancing in a caudal direction), until the posterior atlanto-occipital membrane was located (as a marked decrease in resistance). CSF samples were placed in test tubes containing ethylenediaminetetraacetate $(7.5 \%)$ and centrifuged ( $5000 \mathrm{rpm}, 5 \mathrm{~min}$ ). The supernatant was removed, placed in vials, and stored at $-80^{\circ} \mathrm{C}$ until assay. 5-HIAA concentrations were assayed using HPLC with electrochemical detection (Minano et al., 1989), with inter- and intra-assay variabilities of less than $10 \%$.

\section{Data Analysis}

Mean ethanol and water fluid deliveries were recorded, and the differences in fluid (ethanol/water) deliveries and ethanol intakes were analyzed with three-factor (group, sex, and concentration), within-subjects ANOVA. An alternative analysis of ethanol self-administration was performed by comparing the area under the curve (AUC) that described ethanol and water fluid deliveries and the AUC that described ethanol intake across the tested ethanol concentrations. Briefly, AUC estimates were calculated for each monkey by integrating ethanol and water fluid deliveries or ethanol intake $\left(\mathrm{AUC}_{\mathrm{INT}}\right)$, across ethanol concentrations, using a pharmacological statistical package (Tallarida and Murray, 1987). Ethanol preference was defined as the difference between the ethanol and water fluid delivery curves $\left(\triangle A U C_{F D}\right)$. At some ethanol concentrations, water fluid deliveries were greater than ethanol fluid deliveries for some monkeys. Therefore, in addition to $\triangle \mathrm{AUC}_{\mathrm{FD}}$, individual "corrected" AUCs ( $\triangle A A C_{F D}$ ) were calculated by including only data in which ethanol fluid deliveries were greater than water fluid deliveries. Test/retest reliability measures exceeded $r=0.80$ for all AUC measures.

After rank-ordering of subjects on the basis of ethanol preference or intake, CSF 5-HIAA concentrations were analyzed by one-way (ranking), between-subjects ANOVA. When significant effects were demonstrated, post hoc Newman-Keuls analyses were performed. CSF 5-HIAA concentrations and AUC calculations were analyzed with independent-sample $t$ tests. Pearson product-moment correlation coefficients were determined in the analysis of the relationships among dependent measures. For all comparisons, $\alpha$ was 0.05 (two-tailed).

\section{RESULTS}

\section{One-Spout Oral Self-Administration}

Initially, three cohorts of 13 to 29 monkeys were socially housed in Poolesville and given 1-hr one-spout access to an aspartame-sweetened ethanol solution $(8.4 \%$, w/v). Trained observers noted that all monkeys had free access to
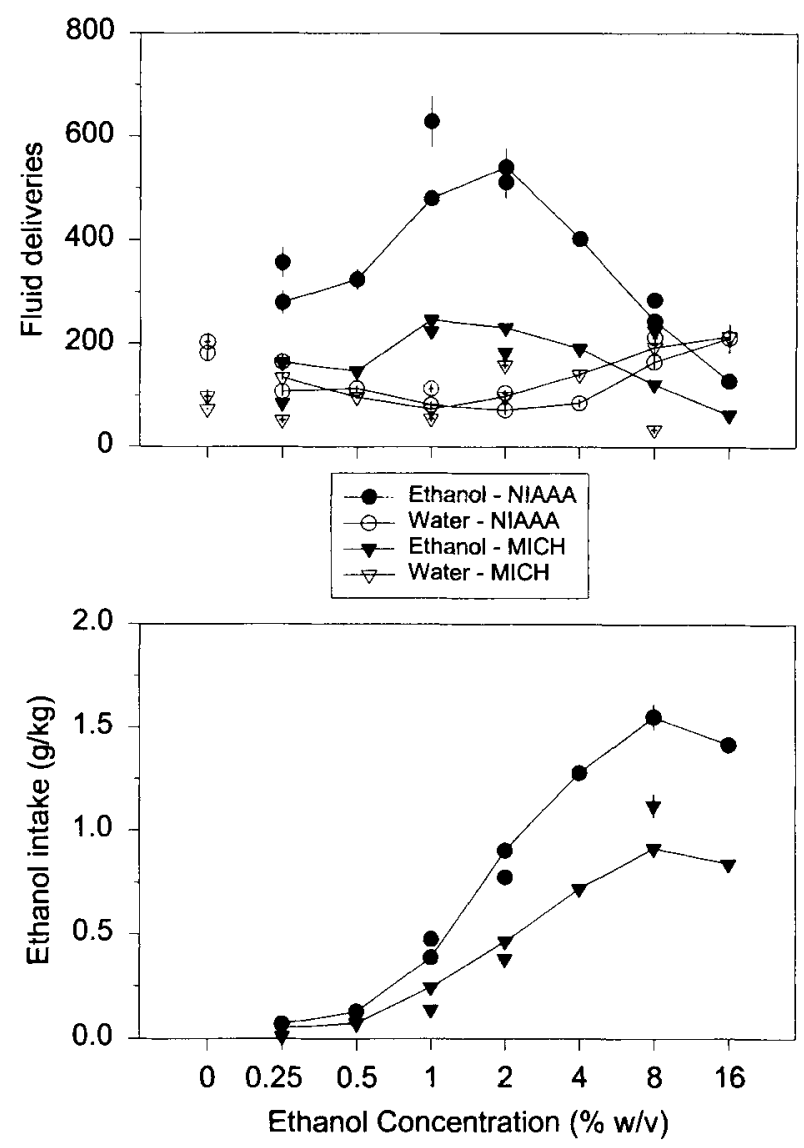

Fig. 2. Top, ethanol and water fluid deliveries for NIAAA and MICH monkeys as a function of ethanol concentration. Bottom, ethanol intake as a function of ethanol concentration. For both panels, error bars denote 1 SEM, and data were derived from two-spout self-administration sessions. Unconnected symbols represent replications of selected ethanol concentrations.

the drinking chamber and spout throughout the drinking session (i.e., physical obstruction of the spout by one or more monkeys did not occur). In these one-spout selfadministration tests, the mean consumption was $1.91 \pm 0.3$ $\mathrm{g} / \mathrm{kg} / \mathrm{hr}$ (mean $\pm \mathrm{SEM}, n=61$ ). The 12 monkeys chosen for the current study were not statistically different from the larger monkey population and consumed $2.29 \pm 0.4 \mathrm{~g} / \mathrm{kg} / \mathrm{hr}$ $[t(60)=0.27, p=0.79]$. Furthermore, ethanol exposure (approximately $44 \mathrm{~g} / \mathrm{kg} /$ monkey from 48 to 51 months of age) did not alter CSF 5-HIAA concentrations [5-HIAA concentration at 48 months, $47.5 \pm 3.3 \mathrm{ng} / \mathrm{ml}$; 5-HIAA concentration at 57 months, $52.9 \pm 4.9 \mathrm{ng} / \mathrm{ml} ; t(11)=0.43$, $p=0.67]$.

\section{Two-Spout Oral Self-Administration}

Fluid Deliveries. In general, an inverted U-shaped curve described ethanol self-administration behavior for both groups of monkeys (Fig. 2, top). Maximal ethanol deliveries were obtained at the 1 and $2 \%(\mathrm{w} / \mathrm{v})$ ethanol concentrations; concurrent water self-administration was unaffected throughout the range of ethanol concentrations. At the highest ethanol concentration, more water than ethanol deliveries were recorded. 
Table 1. Changes in Fluid Deliveries and Ethanol Intake as Functions of Ethanol Concentrations in Rhesus Monkeys

\begin{tabular}{|c|c|c|c|c|c|c|c|}
\hline & \multicolumn{7}{|c|}{ Ethanol concentration $(w / v)$} \\
\hline & $0.25 \%$ & $0.5 \%$ & $1 \%$ & $2 \%$ & $4 \%$ & $8 \%$ & $16 \%$ \\
\hline Ethanol fluid deliveries $(\mathrm{ml})$ & $222 \pm 58$ & $236 \pm 89$ & $364 \pm 117$ & $386 \pm 155$ & $297 \pm 106$ & $184 \pm 61$ & $96 \pm 33$ \\
\hline Water fluid deliveries (ml) & $122 \pm 13$ & $106 \pm 8$ & $78 \pm 4$ & $86 \pm 13$ & $113 \pm 28$ & $179 \pm 14$ & $213 \pm 2$ \\
\hline $\begin{array}{l}\text { Difference in fluid } \\
\text { deliveries }(\mathrm{ml})\end{array}$ & $101 \pm 32$ & $130 \pm 44^{\star}$ & $286 \pm 74^{*}$ & $301 \pm 69^{*}$ & $18 \pm 44^{*}$ & $4 \pm 33$ & $-118 \pm 38$ \\
\hline Ethanol intake $(\mathrm{mg} / \mathrm{kg})$ & $57 \pm 4$ & $92 \pm 8$ & $292 \pm 24^{*}$ & $605 \pm 55^{\star}$ & $923 \pm 60^{*}$ & $1159 \pm 88^{\star}$ & $1060 \pm 51^{*}$ \\
\hline
\end{tabular}

Each value represents the mean \pm SEM for $\operatorname{six}$ sessions for all monkeys $(n=24)$. Asterisks denote significant differences $(\rho<0.05)$ from water/water responding.

Table 2. Statistical Analysis of Ethanol Self-Administration Data for Rhesus Monkeys

\begin{tabular}{|c|c|c|c|}
\hline Factor & $d f$ & $F$ & $p$ \\
\hline \multicolumn{4}{|l|}{ Fluid deliveries } \\
\hline Group & 1,20 & 9.38 & 0.006 \\
\hline Sex & 1,20 & 1.47 & 0.24 \\
\hline Concentration & 7,140 & 14.65 & 0.001 \\
\hline Group $\times$ sex & 1,20 & 1.17 & 0.29 \\
\hline Group $\times$ concentration & 7,140 & 1.85 & 0.82 \\
\hline Sex $\times$ concentration & 7,140 & 0.59 & 0.76 \\
\hline Group $\times \operatorname{sex} \times$ concentration & 7,140 & 0.41 & 0.89 \\
\hline \multicolumn{4}{|l|}{$\Delta \mathrm{AUC}_{\mathrm{FD}}$} \\
\hline Group & 1,20 & 11.91 & 0.003 \\
\hline Sex & 1,20 & 1.04 & 0.32 \\
\hline Group $\times$ sex & 1,20 & 0.76 & 0.39 \\
\hline \multicolumn{4}{|l|}{$\mathrm{c} \triangle \mathrm{AU} \mathrm{C}_{\mathrm{FD}}$} \\
\hline Group & 1. 20 & 10.45 & 0.004 \\
\hline Sex & 1,20 & 2.51 & 0.13 \\
\hline Group $\times$ sex & 1,20 & 1.11 & 0.30 \\
\hline \multicolumn{4}{|l|}{ Intake } \\
\hline Group & 1,20 & 8.38 & 0.009 \\
\hline Sex & 1,20 & 0.03 & 0.86 \\
\hline Concentration & 7,140 & 80.41 & 0.001 \\
\hline Group $\times$ sex & 1,20 & 0.001 & 0.97 \\
\hline Group $\times$ concentration & 7,140 & 5.69 & 0.001 \\
\hline Sex $\times$ concentration & 7,140 & 0.12 & 1.00 \\
\hline Group $\times$ sex $\times$ concentration & 7,140 & 0.72 & 0.66 \\
\hline \multicolumn{4}{|l|}{$\mathrm{AUC}_{\mathrm{INT}}$} \\
\hline Group & 1,20 & 9.70 & 0.005 \\
\hline Sex & 1,20 & 0.001 & 0.97 \\
\hline Group $\times$ sex & 1,20 & 0.01 & 0.92 \\
\hline
\end{tabular}

NIAAA monkeys obtained more fluid deliveries than did their age-matched controls (MICH monkeys) across the tested concentration range $[F(1,20)=9.38, p=0.006]$. Irrespective of the group examined, more ethanol fluid deliveries were obtained with the 0.5 to $4 \%(\mathrm{w} / \mathrm{v})$ ethanol concentrations $[F(7,140)=14.65, p=0.001]$ (Table 1$)$. There were no sex differences or interactions among group, sex, and ethanol concentration with respect to the number of ethanol fluid deliveries obtained (Table 2). Finally, replications with selected ethanol concentrations tested in a varied order were not different from the initial ethanol determinations made in ascending order.

$\triangle \mathrm{AUC}_{\mathrm{FD}}$ and $\mathrm{c} \triangle \mathrm{AUC} \mathrm{C}_{\mathrm{FD}}$ values also demonstrated that NIAAA monkeys obtained more ethanol fluid deliveries (demonstrated a greater ethanol preference) than did MICH monkeys $[F(1,20)=11.91, p=0.003$, and $F(1,20)=$ $10.45, p=0.004$, respectively] (Fig. 3, top and middle). There were no sex differences or interactions between group and sex for these transformed data (Table 2).

Intake. Greater ethanol consumption was demonstrated with increasing concentrations of ethanol, reaching signif-
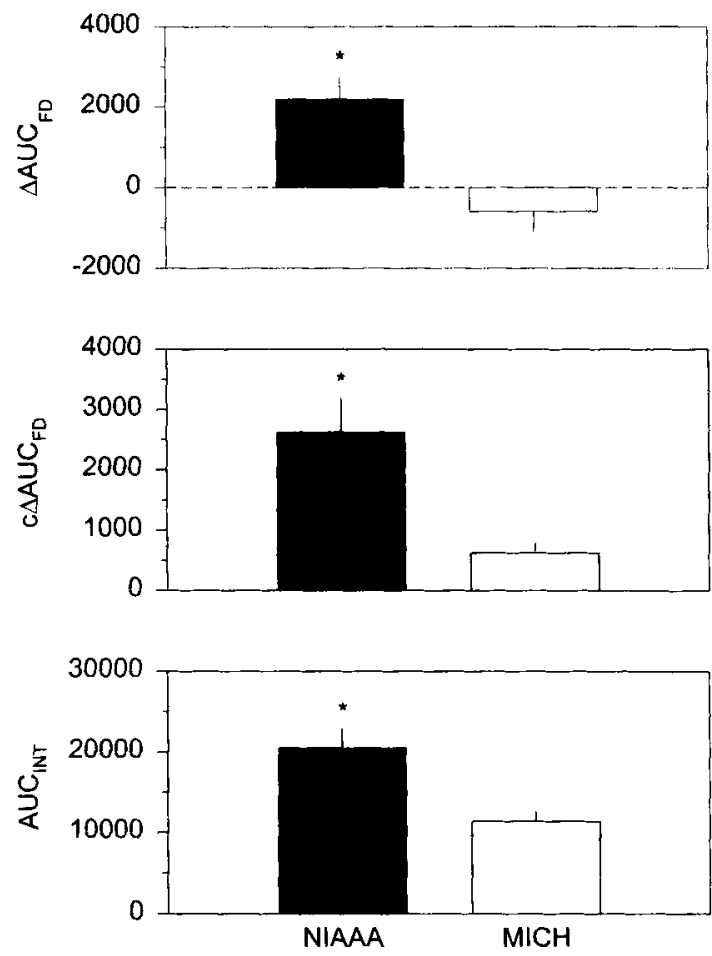

Fig. 3. Top, ethanol preferences $\left(\triangle A \cup C_{F D}\right)$ of NIAAA $(\square)$ and $\mathrm{MICH}(\square)$ monkeys. Middle, ethanol preferences ( $\triangle A A U C_{F D}$ ) of NIAAA and MICH monkeys. Bottom, ethanol intakes $\left(A \cup C_{I_{N T}}\right)$ of NIAAA and MICH monkeys. For all panels, asterisks indicate significant differences $(p<0.05)$ between the groups, error bars denote $1 \mathrm{SEM}$, and data were derived from two-spout self-administration sessions. See text for details of the AUC calculations.

icance from 1 to $16 \%(\mathrm{w} / \mathrm{v})[F(7,140)=80.41, p=0.001]$ (Table 1 and Fig. 2, bottom). For the concentrations tested, NIAAA monkeys consumed more ethanol (grams per kilogram) than did MICH monkeys $[F(1,20)=8.38, p=$ 0.009 ], with the difference reaching significance from 2 to $16 \%(\mathrm{w} / \mathrm{v})[F(7,140)=5.69, p=0.001]$. AUC $_{\text {INT }}$ measurements indicated that NIAAA monkeys consumed more ethanol than did MICH monkeys $[F(1,20)=9.70, p=$ 0.005] (Fig. 3, bottom). As with fluid delivery measurements, there were no sex differences in ethanol consumption or interactions among group, sex, and ethanol concentration (Table 2); replications of selected ethanol concentrations were not different from the first series of ethanol determinations.

$B E C s$. BECs were determined immediately after selected ethanol $(1,2,4$, and $8 \%)$ self-administration sessions and increased linearly with ethanol intake $[r(59)=0.95, p=$ 0.001] (Fig. 4). At the concentration that produced the 


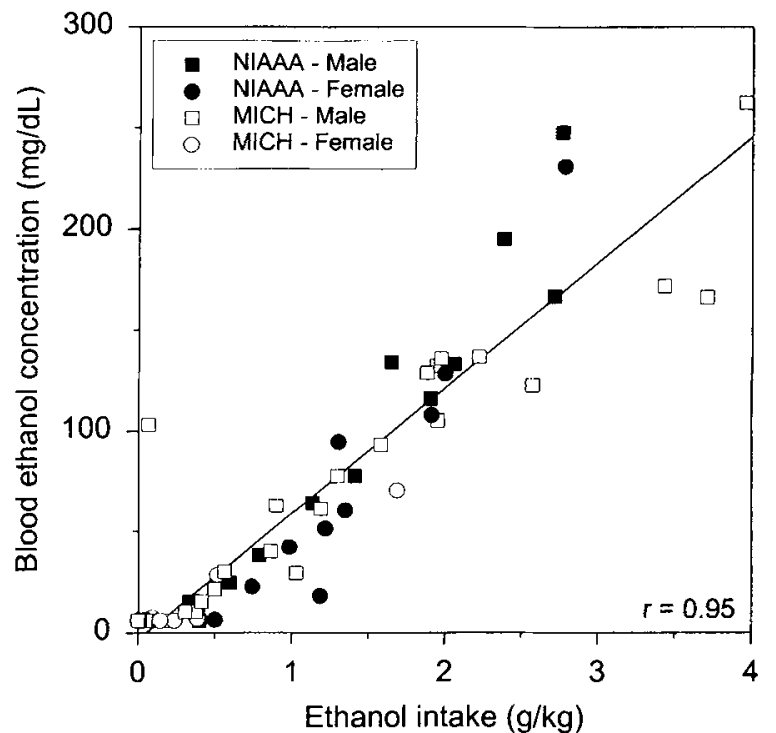

Fig. 4. Correlation between BECs and ethanol intakes. The diagonal line represents a first-order regression equation for the data; the correlation coefficient is indicated at the bottom right. Data were derived from selected two-spout ethanol $(1,2,4$, and $8 \%, w / v)$ self-administration sessions. Separate blood samples (minimum of 2) were obtained within 1 week for each monkey; each point represents the determination for one session.

largest difference between ethanol $(2 \%, \mathrm{w} / \mathrm{v})$ and water fluid deliveries, mean BECs for NIAAA and MICH monkeys were 53.3 and $25.7 \mathrm{mg} / \mathrm{dl}$, respectively. At the concentration that produced the greatest ethanol consumption $(8 \%$, w/v), mean BECs for NIAAA and MICH monkeys were 93.2 and $53.9 \mathrm{mg} / \mathrm{dl}$, respectively.

\section{Behavioral Correlates of Oral Ethanol Self-Administration}

Pearson product-moment correlation coefficients were calculated by comparing fluid deliveries and intakes in oneand two-spout ethanol self-administration paradigms. Oral self-administration was consistent across contexts. NIAAA monkeys that consumed the largest quantities of an aspartame-sweetened ethanol solution $(8.4 \%, \mathrm{w} / \mathrm{v})$ from a single spout while socially housed demonstrated the greatest preferences toward and intakes of unsweetened ethanol, in a two-spout procedure, while individually housed $\left[\mathrm{c} \Delta \mathrm{AUC}_{\mathrm{FD}}, r(12)=0.77, p=0.004 ; \mathrm{AUC}_{\mathrm{INT}}, r(12)=0.86\right.$, $p=0.001]$ (Fig. 5). With two-spout oral self-administration, monkeys that demonstrated the greatest preferences $\left(\mathrm{c} \triangle \mathrm{AUC} \mathrm{FD}_{\mathrm{FD}}\right.$ ) for ethanol over water consumed the most ethanol [AUC $\mathrm{ANT}_{\mathrm{INT}}, r(24)=0.82, p=0.001$ ] (Fig. 6).

\section{CSF 5-HIAA Concentrations and Oral Ethanol Self- Administration}

Overall, lower CSF 5-HIAA concentrations were modestly correlated with increased ethanol preferences [c $\left.\Delta \mathrm{AUC}_{\mathrm{FD}}, r(24)=-0.49, p=0.001\right]$, whereas $\mathrm{CSF}$ 5-HIAA concentrations were not correlated with ethanol intakes $\left[\mathrm{AUC}_{\mathrm{INT}}, r(24)=-0.28, p=0.19\right.$ ]. There was a trend toward lower CSF 5-HIAA concentrations in the
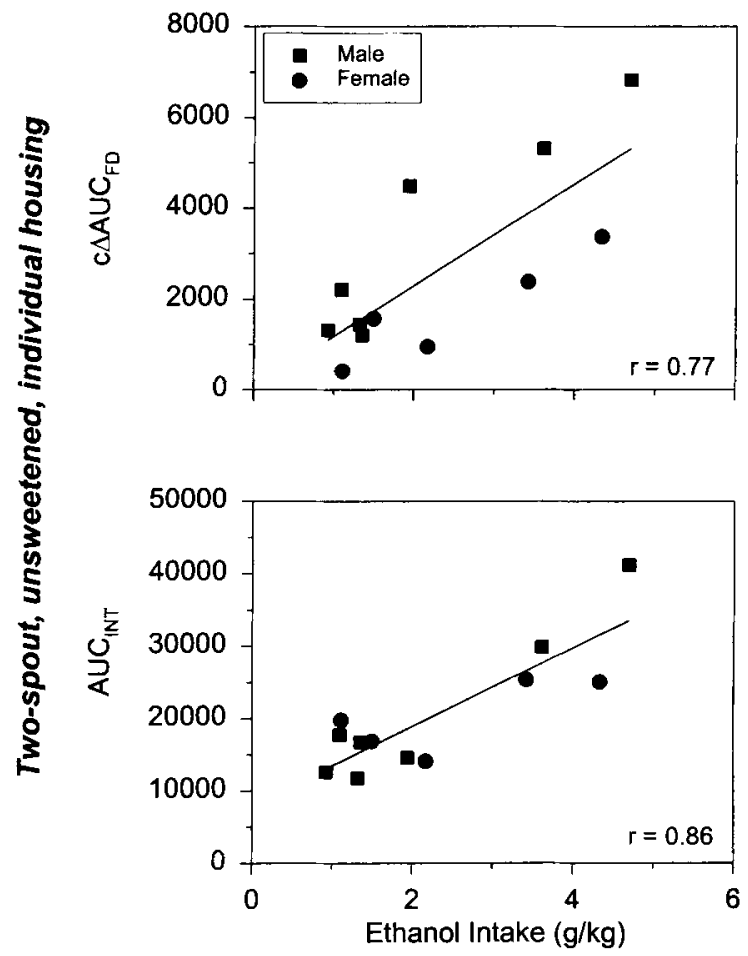

Single-spout, aspartame-sweetened, social setting

Fig. 5. Top, correlation between ethanol preferences $\left(\mathrm{C} \triangle A \cup \mathrm{C}_{\mathrm{FD}}\right)$ in two-spout self-administration sessions and ethanol intakes in one-spout self-administration sessions. Bottom, correlation between ethanol intakes $\left(\mathrm{AUC}_{\mathrm{INT}}\right)$ in two-spout self-administration sessions and ethanol intakes in one-spout self-administration sessions. The diagonal lines represent first-order regression equations for the data, and the correlation coefficients are indicated at the bottom right of each panel.

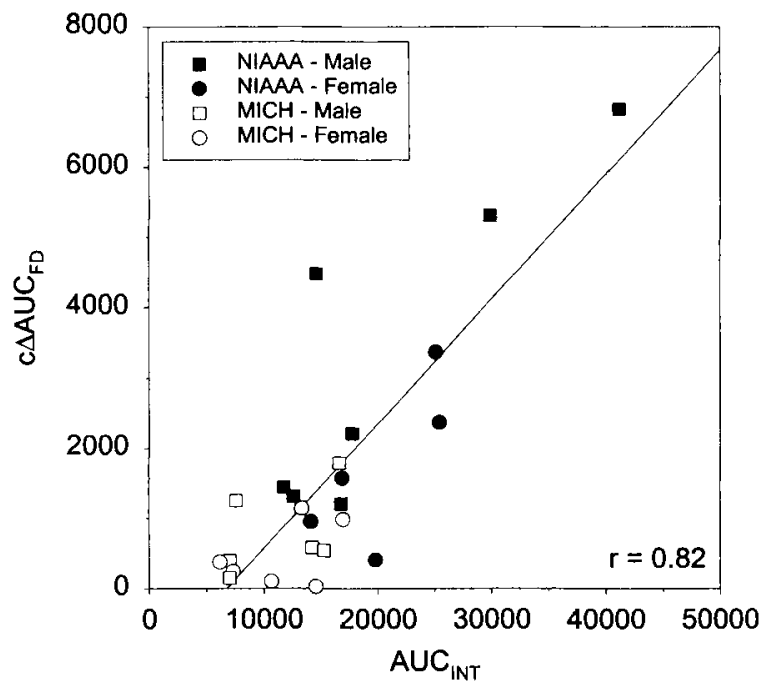

Fig. 6. Correlation between ethanol preferences ( $\triangle A \cup \cup C_{F D}$ ) and intakes $\left(A \cup C_{I N T}\right)$. The diagonal line represents a first-order regression equation for the data, and the correlation coefficient is indicated at the bottom right. Data were derived from two-spout self-administration sessions.

NIAAA monkeys $[t(22)=3.71, p=0.07]$. The large sample size used in the current study allowed for more detailed characterization of monkeys deviating from the average 

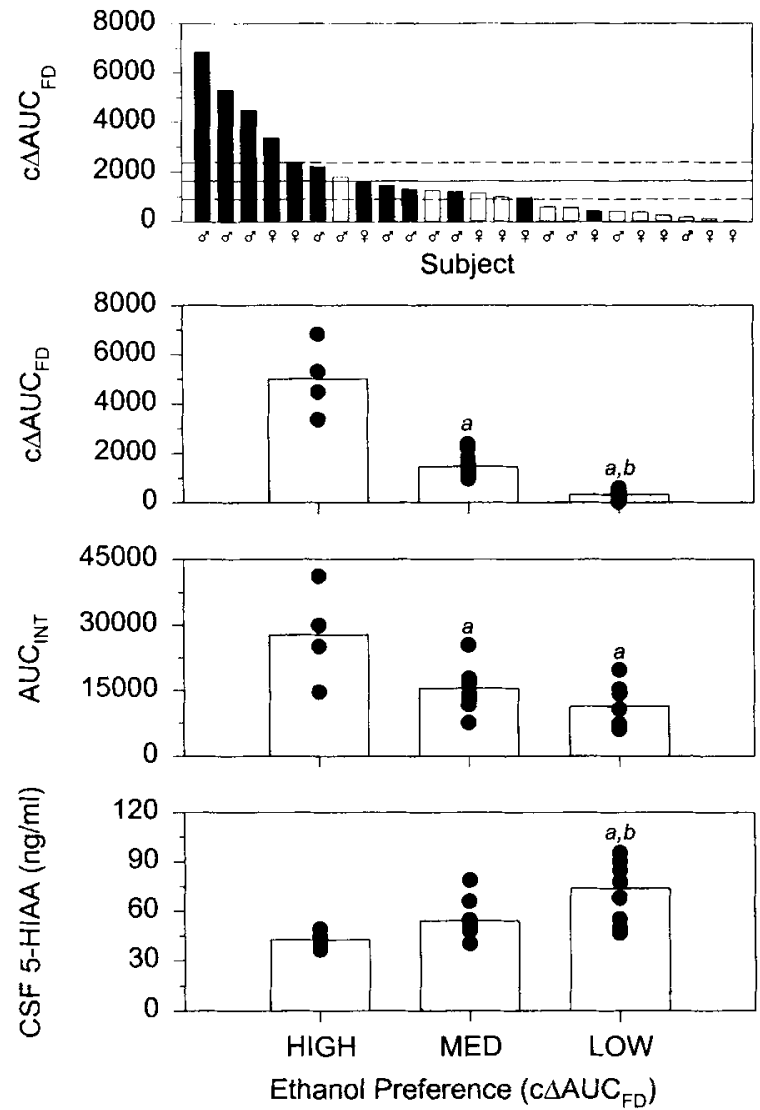

Fig. 7. Top, rank-ordering of the monkeys on the basis of their ethanol preferences (c $\triangle A \cup C_{F O}$ ). Each bar represents one subject (black: N1AAA; white: $\mathrm{MICH}$ ), the horizontal dashed lines represent the $95 \%$ confidence interval associated with the group mean (horizontal solid line), and the sex of each subject is depicted on the abscissa. Top middle, ethanol preferences ( $C A A C_{F D}$ ) as a function of preference ranking. Bottom middle, ethanol intakes $\left(A \cup C_{I N T}\right)$ as a function of preference ranking. Bottom, CSF 5-HIAA concentrations as a function of preference ranking. For the lower three panels, bars represent the mean for each group and filled circles represent the individual subjects. $a$, significant difference $(\rho<0.05$ ) from the high preference (ethanol-preferring) monkeys; $b$, significant difference from the medium preference monkeys. For all panels, data were derived from two-spout self-administration sessions.

ethanol preference and intake for the group. Figure 7 (top) depicts the rank-order ethanol preference $\left(\mathrm{c} \Delta \mathrm{AUC} \mathrm{F}_{\mathrm{FD}}\right)$ for each subject. Monkeys whose ethanol preference fell above, within, and below the $95 \%$ confidence interval associated with the mean for the group were defined as high $(n=4)$, medium $(n=11)$, and low $(n=9)$ ethanolpreferring monkeys, respectively. Although there was substantial overlap in the CSF 5-HIAA concentrations among the groups, low ethanol-preferring monkeys exhibited higher CSF 5-HIAA concentrations than did medium and high ethanol-preferring monkeys $[F(2,21)=8.31, p=$ 0.007] (Fig. 7, bottom).

Figure 8 (top) depicts the rank-order ethanol intake $\left(A U C_{I N T}\right)$ for each subject. Monkeys whose ethanol intake fell above, within, and below the $95 \%$ confidence interval associated with the mean for the group were defined as high $(n=5)$, medium $(n=12)$, and low $(n=7)$ ethanolconsuming monkeys, respectively. In this ranking, there was
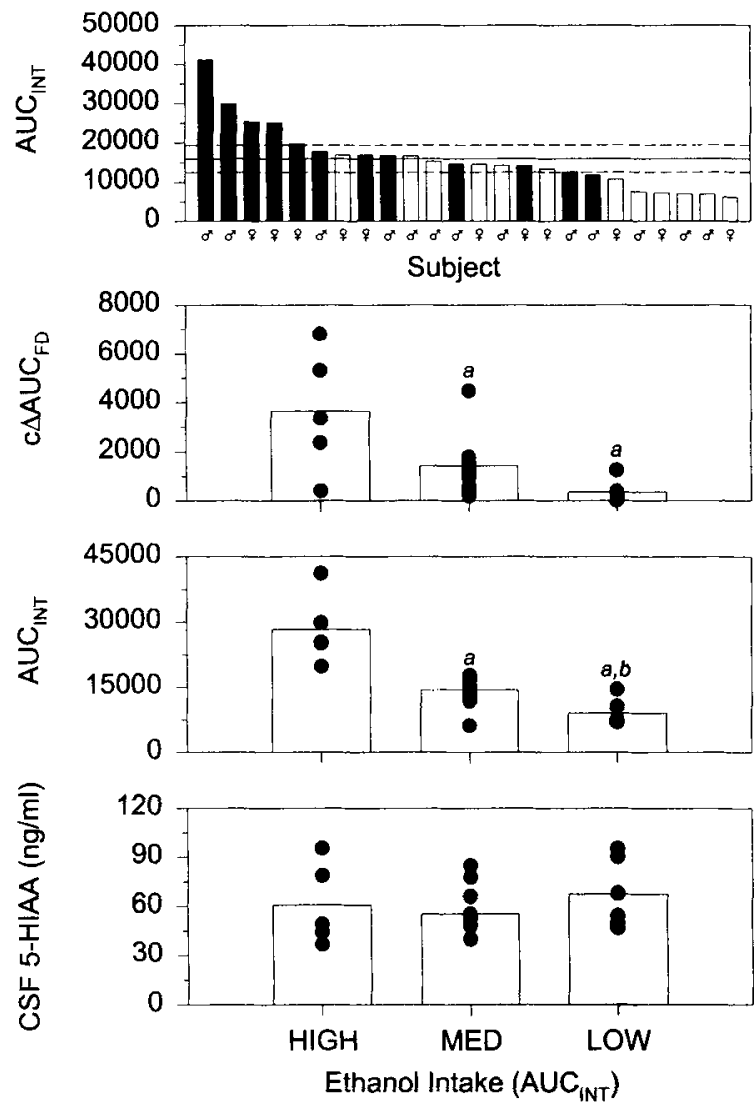

Fig. 8. Top, rank-ordering of the monkeys on the basis of their ethanol intakes $\left(A_{U} C_{I N T}\right)$. Each bar represents one subject (black: N1AAA; white: $\left.M I C H\right)$, the horizontal dashed lines represent the $95 \%$ confidence interval associated with the group mean (horizontal solid line), and the sex of each subject is depicted on the abscissa. Top middle, ethanol preferences ( $C A A C_{\mathrm{FD}}$ ) as a function of intake ranking. Bottom middle, ethanol intakes $\left(A \cup C_{I_{N T}}\right)$ as a function of intake ranking. Bottom, CSF 5-HIAA concentrations as a function of intake ranking. For the lower three panels, bars represent the mean for each group and filled circles represent the individual subjects. a, significant difference $(p<0.05)$ from the high preference (ethanol-preferring) monkeys; $b$, significant difference from the medium preference monkeys. For all panels, data were derived from two-spout selfadministration sessions.

no relationship between intake and CSF 5-HIAA concentrations (Fig. 8, bottom).

\section{DISCUSSION}

Unlike experiments involving intravenous ethanol selfadministration, experiments involving oral ethanol selfadministration are noted for differences in individual propensities to consume ethanol. Subjects respond to ethanol reinforcers at different rates, and their preferences and consumption can vary from water only to ethanol only; in many studies, ethanol intakes fail to produce BECs of pharmacological relevance. Because of these individual differences in the patterns of oral ethanol self-administration, the major focus of this study was to characterize some of the behavioral and neurochemical correlates of oral ethanol self-administration. Monkeys that consumed large amounts of sweetened ethanol in a social setting continued to consume large amounts of unsweetened ethanol while 
individually housed. This result suggests that previous ethanol consumption predicts future ethanol consumption or, phrased differently, that ethanol consumption is stable across contexts. Monkeys with the greatest preferences for ethanol over water self-administered the highest doses of ethanol, which suggests that ethanol preference predicts ethanol consumption. Finally, when monkeys were rankordered on the basis of their ethanol preferences (similar to experiments involving ethanol-preferring lines of rats), CSF 5-HIAA concentrations were highest in those monkeys in which ethanol preferences were the most temperate. This result supports the proposal that CSF 5-HIAA concentrations inversely predict some aspects of ethanol selfadministration behavior.

Individual differences in ethanol consumption were maintained in two very different contexts, which included different housing, self-administration, and age conditions (Fig. 5); these trait-like consistencies for subjects have not been well documented. Consistent ethanol drinking in social and individual settings has been reported for male and female vervet monkeys (Ervin et al., 1990). However, closer inspection of the data revealed inconsistent or poor correlations in the amount of ethanol consumed at yearly intervals [year $1-2, r(12)=0.63$; year $2-3, r(12)=-0.19$; year $1-3, r(12)=0.17]$. At the time of this writing (approximately 30 months after the one-spout ethanol tests), NIAAA monkeys continue to receive two-spout access to ethanol $(2 \%, \mathrm{w} / \mathrm{v})$ and water, and their current ethanol consumption remains highly correlated $[r(12)=0.82, p=0.001]$ with their previous consumption under one-spout access conditions.

The ethanol preferences and intakes observed in this study were in accordance with previous reports of ethanol self-administration in rhesus monkeys (Henningfield and Meisch, 1978). Furthermore, the shapes of the concentrationeffect curves for reinforcers (biphasic) and intake (ascending) and the strong correlation between ethanol consumption and BECs observed in this study (Fig. 4) are consistent with findings from previous investigations using oral ethanol selfadministration (Crowley et al., 1990; Henningfield and Meisch, 1979; Meisch et al., 1975; Stewart et al., 1996), as well as the majority of intravenous self-administration experiments (Deneau et al., 1969; Griffiths et al., 1991; Karoly et al., 1978; Winger and Woods, 1973). However, the relationship between ethanol preferences and intakes has not been well elucidated. In fact, the distinction between behavioral (number of reinforcers obtained) and consumption (intake) preferences has been blurred in many of the animal studies. For example, the original procedure to distinguish $\mathrm{P}$ and NP rats involved $24-\mathrm{hr}$ free-choice exposure to ethanol $(10 \%, \mathrm{w} / \mathrm{v})$ and water; $\mathrm{P}$ rats were identified as those subjects that consumed more than $5 \mathrm{~g} / \mathrm{kg}$ ethanol while demonstrating a strong preference for ethanol over water and NP rats as those subjects that consumed less than $0.5 \mathrm{~g} / \mathrm{kg}$ ethanol without demonstrating a strong preference for ethanol over water (Li et al., 1994). Subsequent research has not consistently maintained the dis- tinction between preferences and intakes; although it is not essential that a subject that preferentially responds to a drug, compared with vehicle, also self-administers large quantities of that drug, these two measures of ethanol selfadministration were highly correlated for individual monkeys in the present study and were not correlated with water selfadministration (Fig. 6). The association between preferences and consumption was also maintained with group, free-choice, drug self-administration procedures in rodents (Amit and Corcoran, 1975; Lankford et al., 1991; Sinclair et al., 1992).

Without special induction procedures (e.g., sucrose fading or schedule-induced polydipsia), all monkeys in the current two-spout self-administration study demonstrated ethanol preferences, either at a specific concentration or at many concentrations. Four of the monkeys (17\%) demonstrated ethanol preferences outside the mean and associated $95 \%$ confidence interval for the group. These were identified as ethanol-preferring monkeys, and BECs above $100 \mathrm{mg} / \mathrm{dl}$ were consistently attained when the monkeys were exposed to the higher ethanol concentrations (4$16 \%, \mathrm{w} / \mathrm{v})$. Among a larger group of 50 rhesus monkeys (including the 24 subjects from the present study) maintained in our laboratory, the proportion of ethanolpreferring monkeys is conserved at $18 \%$. This proportion of ethanol-preferring monkeys is similar to that observed for "spontaneously drinking" vervet monkeys ( $17 \%$ of a sample of 196 monkeys) (Ervin et al., 1990) and actually exceeds the 3 to $10 \%$ lifetime prevalence for alcoholism among human subjects (O'Brien, 1996).

Compromised 5-HT function has been proposed as a "marker" for alcoholism and alcohol abuse (Ballenger et al., 1979; Cloninger, 1987). Consistent with this proposal was the observation that ethanol preferences and consumption were inversely related to CSF 5-HIAA concentrations (after rank-ordering of the monkeys on the basis of their preferences) (Fig. 7). Although there was substantial overlap in the individual CSF 5-HIAA concentrations among high, medium, and low ethanol-preferring monkeys, low ethanol-preferring monkeys demonstrated much higher group CSF 5-HIAA concentrations. This result is concordant with studies in which decreased 5-HT and 5-HIAA concentrations in various brain regions were demonstrated for P rats (Gongwer et al., 1989; Murphy et al., 1982), and it provides supportive evidence for the validity of rankordering monkeys on the basis of their ethanol preferences.

Although ethanol preferences were correlated with ethanol intakes as well as lower CSF 5-HIAA levels, there was no correlation between ethanol intakes and CSF 5-HIAA concentrations (Fig. 8). A review of the literature evaluating the relationship between 5 -HT levels and alcohol intake revealed that, for the most part, increases in synaptic 5-HT concentrations produced by releasing agents, reuptake blockade, or autoreceptor blockade decreased ethanol intakes for human subjects, nonhuman primates, and rodents (McBride et al., 1988; Naranjo et al., 1994; Yu et al., 1997; Zhou et al., 1998). Alternatively, decreases in postsynaptic 
5-HT effects with the 5- $\mathrm{HT}_{2}$ antagonist methysergide increased ethanol intakes in rats (Lu et al., 1994; but see Weiss et al., 1990). However, there is some doubt regarding the ethanol selectivity of these 5-HT manipulations (Higgins et al., 1992; Higley et al., 1998; Lu et al., 1994), and decreases in 5-HT levels with the 5-HT neurotoxin 5,7dihydroxytryptamine and the 5-HT-depleting agent $p$-chlorophenylalanine have not always produced consistent or significant increases in ethanol intake (Adell and Myers, 1996; LeMarquand et al., 1994; Wang et al., 1996). Furthermore, ongoing research within our laboratory revealed that chronic administration of the 5-HT-releasing agent fenfluramine ( $3.2 \mathrm{mg} / \mathrm{kg} /$ day for 4 months), which produced 30 to $60 \%$ decreases in plasma 5-HT levels, consistently decreased ethanol intake. Because CSF 5-HIAA concentrations provide only an indirect measure of central 5-HT function and favor 5-HT release in circumventricular structures, further research must be performed, particularly involving the continuing investigation of central sites important in 5-HT activity (McBride et al., 1995, 1997) and the use of newer 5-HT-selective ligands.

In this study we have included novel assessments of self-administration behavior $\left(\triangle A U C_{F D}, c \Delta A U C_{F D}\right.$, and $A U C_{\text {INT }}$ ), which we think indicate drug preferences and intakes (Fig. 3). AUC calculations, although not typically used in oral self-administration research, have proven to be useful and valid measurements in pharmacological research involving comparisons of the time courses of drug actions (i.e., pharmacokinetics) (Neubig, 1990). The preference AUC and $\mathrm{AUC}_{\mathrm{INT}}$ estimates were consistent with traditional depictions of drug preferences (fluid deliveries) and intakes and demonstrated good test/retest reliability. We propose that these AUC estimates more thoroughly describe self-administration behavior, because they encompass the complete concentration-effect assessment and provide a single measure for ethanol preferences and intakes. These AUC parameters allow convenient comparisons with other behavioral and neurochemical measures.

In conclusion, the present experiments characterized a few of the behavioral and neurochemical correlates of oral ethanol self-administration in rhesus monkeys. Individual differences in ethanol preferences and consumption were found to be consistent for the monkeys; previous ethanol consumption predicted later consumption (and continues to do so), ethanol preferences over water were correlated with ethanol consumption, and CSF 5-HIAA concentrations were inversely related to ethanol preferences.

\section{REFERENCES}

Adell A, Myers RD (1996) Lesioning of midbrain raphe nuclei with 5,7-DHT fails to alter ethanol intake in the low alcohol drinking (LAD) rat. Prog Neuropsychopharmacol Biol Psychiatry 20:473-481.

Amit Z, Corcoran ME (1975) Regulation of cthanol intake by rats with an induced preference for ethanol. Neuropharmacology 14:685-691.

Ballenger JC, Goodwin FK, Major LF, Brown GL (1979) Alcohol and central serotonin metabolism in man. Arch Gen Psychiatry 36:224-227.
Borg S, Kvande H, Liljeberg P, Mossberg D, Valverius P (1985) 5-Hydroxyindoleacetic acid in cerebrospinal fluid in alcoholic patients under different clinical conditions. Alcohol 2:415-418.

Carroll ME, Stotz DC (1983) Oral $d$-amphetamine and ketamine selfadministration by rhesus monkeys: Effects of food deprivation. J Pharmacol Exp Ther 227:28-34.

Cloninger CR (1987) Neurogenetic adaptive mechanisms in alcoholism. Science (Wash. DC) 236:410-416.

Collins DM, Myers RD (1987) Buspirone attenuates volitional alcohol intake in the chronically drinking monkey. Alcohol 4:49-56.

Crowley TJ, Williams EA, Jones RH (1990) Initiating ethanol drinking in a simian social group in a naturalistic setting. Alcohol Clin Exp Res 14:444-455.

Deneau G, Yanagita T, Seevers MH (1969) Self-administration of psychoactive substances by the monkey. Psychopharmacologia 16:30-48.

Devoto P, Colombo G, Stefanini E, Gessa GL (1998) Serotonin is reduced in the frontal cortex of Sardinian ethanol-preferring rats. Alcohol Alcohol 33:226-229.

Erikkson K (1972) Behavioral and physiological differences among rat strains specially selected for their alcohol consumption. Ann NY Acad Sci 197:32-41.

Ervin FR, Palmour RM, Young SN, Guzman-Flores C, Juarez J (1990) Voluntary consumption of beverage alcohol by vervet monkeys: Population scrcening, descriptive behavior and biochemical measures. Phatmacol Biochem Behav 36:367-373.

Gongwer MA, Murphy JM, McBride WJ, Lumeng L, Li T-K (1989) Regional brain contents of serotonin, dopamine and their metabolites in the selectively bred high- and low-alcohol drinking lines of rats. Alcohol 6:317-320.

Griffiths RR, Lamb RJ, Sannerud CA, Ator NA, Brady JV (1991) Selfinjection of barbiturates, benzodiazepines and other sedative-anxiolytics in baboons. Psychopharmacology (Berlin) 103:154-161.

Heinz A, Ragan P, Jones DW, Hommer D, Williams W, Knable MB, Gorey JG, Doty L, Geyer C, Lee KS, Coppola R, Weinberger DR, Linnoila M (1998) Reduced central serotonin transporters in alcoholism. Am J Psychiatry 155:1544-1549.

Henningfield JE, Meisch RA (1976) Ethanol as a positive reinforcer via the oral route for rhesus monkeys: Maintenance of fixed-ratio responding. Pharmacol Biochem Behav 4:473-475.

Henningfield JE, Meisch RA (1978) Ethanol drinking by rhesus monkeys as a function of concentration. Psychopharmacology (Berlin) 57:133136.

Henningfield JE, Meisch RA (1979) Ethanol drinking by rhesus monkeys with concurrent access to water. Pharmacol Biochem Behav 10:777-782.

Higgins GA, Tomkins DM, Fletcher PJ, Sellers EM (1992) Effect of drugs influencing 5-HT function on ethanol drinking and feeding behaviour in rats: Studies using a drinkometer system. Neurosci Biobehav Rev 16: 535-552.

Higley JD, Hasert MF, Suomi SJ, Linnoila M (1991) Nonhuman primate model of alcohol abuse: Effects of early experience, personality, and stress on alcohol consumption. Proc NatI Acad Sci USA 88:7261-7265.

Higley JD, Hasert M, Suomi SJ, Linnoila M (1998) The serotonin reuptake inhibitor sertraline reduces excessive alcohol consumption in nonhuman primates: Effects of stress. Neuropsychopharmacology (Berlin) 18:431-443.

Higley JD, Suomi SJ, Linnoila M (1996) A nonhuman primate model of type II excessive alcohol consumption? 1. Low cerebrospinal fluid 5-hydroxyindoleacetic acid concentrations and diminished social competence correlate with excessive alcohol consumption. Alcohol Clin Exp Res 20:629-642.

Juarez J, Guzman-Flores C, Ervin FR, Palmour RM (1993) Voluntary alcohol consumption in vervet monkeys: Individual, sex and age differences. Pharmacol Biochem Behav 46:985-988.

Karoly AJ, Winger G, Ikomi F, Woods JH (1978) The reinforcing properties of ethanol in the rhesus monkey. II. Some variables related to the maintenance of intravenous ethanol-reinforced responding. Psychopharmacology (Berlin) 58:19-25. 
Kraemer GW, McKinney WT (1985) Social separation increases alcohol consumption in rhesus monkeys. Psychopharmacology (Berlin) 86:182189.

Lankford MF, Roscoe AK, Pennington SN, Myers RD (1991) Drinking of high concentrations of ethanol versus palatable fluids in alcoholpreferring (P) rats: Valid animal model of alcoholism. Alcohol 8:293299.

LeMarquand D, Pihl RO, Benkelfat C (1994) Serotonin and alcohol intake, abuse, and dependence: Findings of animal studies. Biol Psychiatry $36: 326-337$.

Li T-K, Lumeng L, McBride WJ, Murphy JM (1994) Genetic and neurobiological basis of alcohol-seeking behavior. Alcohol Alcohol 29:697700.

Lu MR, Wagner GC, Fisher H (1994) Ethanol consumption following acute treatment with methysergide, fluoxetine, fenfluramine, and their combination. Alcohol Clin Exp Res 18:60-63.

Mardones J, Segovia-Riquelme N (1983) Thirty-two years of selection of rats for ethanol preference: UchA and UchB strains. Neurobehav Toxicol Teratol 5:171-178.

McBride WJ, Bodart B, Lumeng L, Li TK (1995) Associations between low contents of dopamine and serotonin in the nucleus accumbens and high alcohol preference. Alcohol Clin Exp Res 19:1420-1422.

McBride WJ, Chernet E, Russell RN, Chamberlain JK, Lumeng L, Li TK (1997) Regional CNS densities of serotonin and dopamine receptors in high alcohol-drinking (HAD) and low alcohol-drinking (LAD) rats. Alcohol 14:603-609.

McBride WJ, Murphy JM, Lumeng L, Li TK (1988) Effects of Ro15-4513, fluoxetine and desipramine on the intake of ethanol, water and food by the alcohol-preferring (P) and -nonpreferring (NP) lines of rats. Pharmacol Biochem Behav 30:1045-1050.

Meisch RA, Henningfield JE, Thompson T (1975) Establishment of ethanol as a reinforcer for rhesus monkeys via the oral route: Initial results. Adv Exp Med Biol 59:323-342.

Minano FJ, Peinado JM, Myers RD (1989) Neurotensin perfused in hypothalamus of sated or fasted rat: HPLC analysis of release of DA, $\mathrm{NE}$ and 5-HT and their metabolites. Peptides 9:1381-1387.

Murphy JM, McBride WJ, Lumeng L, Li T-K (1982) Regional brain levels of monoamines in alcohol-preferring and -nonpreferring lines of rats. Pharmacol Biochem Behav 16:145-149.

Murphy JM, McBride WJ, Lumeng L, Li T-K (1987) Contents of monoamines in forebrain regions of alcohol-preferring (P) and -nonpreferring (NP) lines of rats. Pharmacol Biochem Behav 26:389392.

Naranjo CA, Poulos CX, Bremmer KE, Lanctot KL (1994) Fluoxetine attenuates alcohol intake and desire to drink. Int Clin Psychopharmacol 9:163-172.

Neubig RR (1990) The time course of drug action, in Principles of Drug Action: The Basis of Phamacology (Pratt WB, Taylor P eds) 3rd ed, pp 297-363, Churchill Livingstone, New York.

O'Brien CP (1996) Drug addiction and drug abuse, in The Pharmacological Basis of Therapeutics (Hardman JG, Limbird LE, Molinoff PB,
Ruddon RW, Gilman AG eds) 9th ed, pp 557-580, McGraw-Hill, New York.

Prescott CA, Kendler KS (1999) Genetic and environmental contributions to alcohol abuse and dependence in a population-based sample of male twins. Am J Psychiatry 156:34-40.

Rezvani AH, Overstreet DH, Janowsky DS (1990) Genetic serotonin deficiency and alcohol preference in the Fawn-Hooded rats. Alcohol Alcohol 25:573-575.

Sinclair JD, Kampov-Polevoy A, Stewart R, Li T-K (1992) Taste preferences in rat lines selected for low and high alcohol consumption. Alcohol 9:155-160.

Stewart RB, Bass AA, Wang NS, Meisch RA (1996) Ethanol as an oral reinforcer in normal weight rhesus monkeys: Dose-response functions. Alcohol 13:341-346.

Tallarida RJ, Murray RB (1987) Manual of Pharmacologic Calculations with Computer Programs. 2nd ed. Springer-Verlag, New York.

Virkkunen M, Rawlings R, Tokola R, Poland RE, Guidotti A, Nemeroff C, Bissette G, Kalogeras K, Karonen SL, Linnoila M (1994) CSF biochemistries, glucose metabolism, and diurnal activity rhythms in alcoholic, violent offenders, fire setters, and healthy volunteers. Arch Gen Psychiatry 51:20-27.

Wang JY, Shum AY, Lin TC, Wang Y (1996) Central serotonergic lesions increase voluntary alcohol consumption in Sprague Dawley rats: Moderation by long-term ethanol administration. Alcohol Clin Exp Res 20:1252-1259.

Weiss F, Mitchiner M, Bloom FE, Koob GF (1990) Free-choice responding for ethanol versus water in alcohol preferring $(P)$ and unselected Wistar rats is differentially modified by naloxone, bromocriptine, and methysergide. Psychopharmacology (Berlin) 101:178-186.

Williams KL, Winger G, Pakarinen ED, Woods JH (1998) Naltrexone reduces ethanol- and sucrose-reinforced responding in rhesus monkeys. Psychopharmacology (Berlin) 139:53-61.

Winger G (1988) Effects of ethanol withdrawal on ethanol-reinforced responding in rhesus monkeys. Drug Alcohol Depend 22:235-240.

Winger G, Woods JH (1973) The reinforcing properties of ethanol in the rhesus monkey. I. Initiation, maintenance and termination of intravenous ethanol-reinforced responding. Ann NY Acad Sci 215:162-165.

Yoshimoto KY, Komura S (1989) Genetic differences in the effects of voluntary ethanol consumption on brain monoamine levels in inbred strains of mice. Alcohol Alcohol 24:225-229.

Yu YL, Fisher H, Sekowski A, Wagner GC (1997) Amphetamine and fenfluramine suppress ethanol intake in ethanol-dependent rats. Alcohol 14:45-48.

Zernig G, Lewis JW, Woods JH (1997) Clocinnamox inhibits the intravenous self-administration of opioid agonists in rhesus monkeys: Comparison with effects on opioid agonist-mediated antinociception. Psychopharmacology (Berlin) 129:233-242.

Zhou FC, McKinzie DL, Patel TD, Lumeng L, Li T-K (1998) Additive reduction of alcohol drinking by 5-HT1A antagonist WAY 100635 and serotonin uptake blocker fluoxetine in alcohol-preferring $\mathbf{P}$ rats. Alcohol Clin Exp Res 22:266-269. 